DOI 10.37882/2223-2982.2022.01.21

\title{
ЯЗЫКОВЫЕ ЧЕРТЫ 'АНАЛИТИЧНОСТЬ' И 'СИНТЕТИЧНОСТЬ' В СТРУКТУРЕ ЯЗЫКОВОЙ ЛИЧНОСТИ ПЕРЕВОДЧИКА С.А. СТЕПАНОВА
}

\section{LINGUISTIC FEATURES 'ANALYTICITY' AND 'SYNTHETICITY' IN THE STRUCTURE OF TRANSLATOR'S LINGUISTIC PERSONALITY OF S.A. STEPANOV}

\section{A. Pavlenko}

Summary:The article is devoted to the study of translation transformations carried out by S.A. Stepanov in the process of translating the G.G. Byron's 'Darkness' poem, specifically, the transformations that characterize the linguistic traits 'analyticity' and 'syntheticity' in the structure of his linguistic personality of a translator. Based on the analysis of practical material through the use of a semantico-structural approach, the types of meaning transformations that signal the manifestation of linguistic traits 'analyticity' or 'syntheticity' are revealed. The concept of V.V. Bogdanov was chosen to determine the tools of the translation transformations semantico-structural analysis. As a result of the study, it was identified that transformations of meanings system of the original poem that represent the manifestation of the above-mentioned linguistic features, are additions of predicate or non-predicate signs found in the translation text, as well as omissions of signs present in the original work.

Keywords: translator's linguistic personality, linguistic features, analyticity, syntheticity, semantic roles, semantic structure.

\author{
Павленко Александр Игоревич \\ ФГБОУ ВО 'Калужский государственный университет \\ им. К.Э. Циолковского', г. Калуга \\ pavlenko199507@mail.ru
}

Аннотация: Статья посвящена исследованию переводческих преобразований, осуществлённых С.А. Степановым в процессе перевода поэмы Дж.Г. Байрона 'Darkness' и характеризующих языковые черты 'аналитичность' и 'синтетичность' в структуре его языковой личности переводчика. На основании анализа практического материала путём применения семантико-структурного подхода выявляются типы преобразований смысла, сигнализирующие о проявлении языковых черт 'аналитичность' или 'синтетичность'. Для определения инструментария семантико-структурного анализа переводческих преобразований выбрана концепция В.В. Богданова. В результате исследования выявлено, что преобразования системы смыслов оригинального произведения, сообщающие о проявлении вышеупомянутых языковых черт, представляют собой добавления предикатных или непредикатных знаков, обнаруживаемые в тексте перевода, а также опущения знаков, присутствующих в оригинальном произведении.

Ключевые слова: языковая личность переводчика, языковые черты, аналитичность, синтетичность, семантические роли, семантическая структура.
$\Pi$ ереключение интересов исследователей с объекта познания на его субъект стало неотъемлемой характеристикой современной научной парадигмы. В рамках лингвистической науки всё большее внимание уделяется человеку - субъекту языковой деятельности. Данный факт нашёл отражение в концепции 'языковой личности'. Ю.Н. Караулов определяет это понятие как «вид полноценного представления личности, включающий в себя психические, социальные и другие компоненты, преломлённые через её дискурс» [1, с. 86]. Языковая личность переводчика является одним из видов языковой личности в её широком понимании.

Данное исследование опирается на концепцию С.А. Сухих, ключевым элементом которой является понятие 'языковой черты'. Эта категория определяется последним как «повторяющаяся особенность вербального поведения человека, склонного к определённому способу его реализации на экспонентном (формальном), субстанциональном и интенциональном уровнях дискурса» [2, с. 109]. В данной статье подробно анализируются язы- ковые черты 'аналитичность' и 'синтетичность', которые располагаются на субстанциональном уровне дискурса [2, с. 113]. Данный уровень дискурса включает в себя семантический параметр, который С.А. Сухих обозначает как «объём референции семантических единиц» $[2$, с. 110]. Именно объём референции подвергается изменениям в случае осуществления переводчиком особого рода преобразований исходных смысловых структур, которые будут подробно рассмотрены ниже.

Информацию о языковой личности отдельного переводчика нам дают конкретные межъязыковые преобразования, осуществлённые им в процессе создания текста перевода на основе оригинального произведения. С целью же выявления сути переводческих преобразований в процессе анализа текстового материала необходимо осуществлять переход от поверхностной структуры к структуре глубинной, к системе смыслов оригинала и перевода.

Для определения инструментария такого анализа 
переводов выбрана концепция В.В. Богданова [3]. Он выделяет два типа знаков: предикатные и непредикатные. В семантической структуре предикатных знаков в качестве конституирующих, всегда будут выступать семы 'свойство' или 'отношение'. Непредикатные знаки обозначают предметы в собственном смысле этого слова. Их основной семантический признак - 'вещность'. В синтаксической структуре непредикатные знаки выступают в роли актантов (см. также: [4]), которым присваиваются так называемые 'семантические роли'; их выделено 14: агентив, пациентив, бенефициатив, экспериенсив, объектив, инструментатив, медиатив, элементив, перцептив, композитив, ономасиатив, локатив, дескриптив и результатив [3, с. 29-69].

В качестве материала исследования выступает поэма Дж.Г. Байрона 'Darkness' и её перевод, выполненный С.А. Степановым. Переводческие преобразования смысла анализируются путём применения семантико-структурного подхода.

Языковая черта 'аналитичность' обнаруживает себя, когда ситуация, представленная в оригинале, детализируется в тексте перевода. Детализация ситуации осуществляется путём добавления различных элементов смысла к исходной ситуации. Данные элементы смысла являются семантемами (содержательной стороной) предикатных или непредикатных знаков.

Языковая черта 'аналитичность', таким образом, представлена добавлением различных типов предикатных и непредикатных знаков к исходной структуре. Это, в первую очередь, добавление глагольного предиката действия в синтаксической функции однородного сказуемого к предикатному выражению в оригинале: the start did wander [5] - звёзды покосились и разбрелись [6].

Частотным является добавление предиката состояния или свойства к исходному актанту, к примеру: in gloom [5] - в кромешном мраке [6] (в данном случае происходит добавление предиката свойства к актанту в семантической функции 'локатив', который представлен предикатом-существительным). Следующий пример иллюстрирует добавление предиката свойства к актанту в семантической роли 'агентив': and War <...> did glut himself again [5] - жестокая война <...> брала mеnерь своё [6]. В данном случае предикат состояния добавляется к актанту в функции 'экспериенсив': Darkness had no need of aid from them [5] - не было в них нужды восставшей Тьме [6]. На следующем примере можно проследить добавление предиката состояния к актанту в семантической функции 'дескриптив': a chaos of <...> clay [5] - мёртвый хаос праха [6]. Следующее преобразование оригинальной структуры имеет более сложный характер: some <...> smil'd [5] - кто с улыбкой дикой [6]. Глагольный предикат действия оригинала преобразо- ван в предикат-существительное действия в переводе: 'to smile' - 'улыбка'. Предикат-существительное в переводе позволяет присоединить к себе предикат свойства 'дикая'. Таким образом, предикативная единица оригинала была заменена на единицу с ярко выраженным номинативным характером, что и позволило осуществить добавление вышеупомянутого адъективного предиката свойства.

Показателем языковой черты 'аналитичность' также является добавление актанта к исходному предикатному выражению. К примеру: no love was left [5] - любовь они забыли [6]. В данном случае происходит изменение семантики глагольного предиката, что, в свою очередь, сопровождается изменением состава и характера актантов при нём. В оригинальной структуре присутствует нулевой актант в функции 'агентив', который выполнил действие 'to leave'. В переводе добавляется актант 'они' в роли 'пациентив' - одушевлённый аргумент в состоянии, которое выражается предикатом [3, с. 52]. Следующие примеры показывают добавление к исходной структуре актанта в функции 'пациентив': the hand [5] - длань хозяина [6]; vipers $\langle\ldots>$ twin'd themselves $<\ldots$. stingless [5] - аспиды <...> свивались <...> не жаля никого [6] (добавление актанта стало возможным вследствие преобразования предиката свойства 'stingless' в глагольный предикат действия 'жалить'). На данном примере можно проследить добавление к исходному предикатному выражению актанта в функции 'агентив': forests were set on fire [5] - леса они в безумье подожгли [6]. Оригинальная конструкция содержит нулевой актант в функции 'агентив' - в переводе актант в данной семантической роли присутствует на поверхностной структуре. Кроме того, осуществлено добавление предиката-существительного состояния 'в безумье', что также является показателем языковой черты 'аналитичность'.

Частотными являются добавления различного рода наречий-сирконстант к исходным глагольным предиката действия. К примеру, добавление наречия-сирконстанты образа действия: licking the hand [5] - тщетно он лизал немую длань хозяина [6]; and howl'd [5] - и тихо выли [6]; look'd up <...> on the dull sky [5] - глядели беспрестанно в глухую твердь [6]; some <...> wept [5] - кто тихо плакал [6]. Кроме того, выявлен случай добавления наречия-сирконстанты времени: extinguish'd [5] гасли тут же [6].

Помимо добавления наречий-сирконстант, частотным также является присоединение сирконстант в синтаксической функции обстоятельства к исходным глагольным предикатам действия. Это, в первую очередь, сирконстанты места: fell down piecemeal [5] - по кускам обваливались за борm [6]; shriek'd, and died [5] - с воплем пали замертво в золу [6]. Помимо этого, обнаруживаются добавления сирконстант образа действия, к примеру: 
men died [5] - тысячами гибли (люди) [6].

Единичными являются случаи добавления кванторов к исходным актантам (they were enemies [5] - то были два врага [6], числовой квантор), а также добавление частицпредикатов к исходным предикатным выражениям (was a lump [5] - лишь месиво осталось [6], ограничительная частица).

Языковая черта 'синтетичность' проявляется в том случае, когда степень обобщённости ситуации, представленной в переводе, выше, чем степень обобщённости исходной ситуации. Обобщение обнаруживается в случаях опущения смысловых элементов оригинального произведения. Стоит отметить, что опускаются те же разновидности предикатных и непредикатных знаков, добавление которых сигнализировало о проявлении языковой черты 'аналитичность'. В первую очередь, это опущение глагольного предиката действия в синтаксической функции однородного сказуемого, входящего в состав исходного предикатного выражения: the wild birds shriek'd and <...> flutter [5] - надрывались птицы [6]. Многочисленными являются случаи опущения предикатов состояния или свойства при исходном актанте. Например: the stars did wander darkling [5] - звёзды <...> разбрелись [6] (опущение предиката состояния при актанте в функции 'агентив'). Отметим, что актант 'stars' выполняет действие 'wander', которое свойственно одушевлённому субъекту. В результате такого метафорического переноса данному участнику ситуации можно присваивать семантическую роль 'агентив' [3, с. 75]. На следующем примере обнаруживается опущение предиката свойства при актанте в роли 'локатив': nothing stirr'd within their silent depths [5] - ничто не колыхало их глубин [6]. В следующем случае происходит опущение предиката состояния при актанте в семантической функции 'объектив': ships sailorless lay rotting on the sea [5] - суда недвижно гнили в океане [6]. На данном примере видим опущение предиката свойства при актанте в функции 'медиатив': with their cold skeleton hands [5] - холодными руками [6].

Частотным типом преобразования, сигнализирующим о языковой черте 'синтетичность', является опущение исходного актанта, являющегося компонентом предикатного выражения оригинального произведения. Например: the brows of men [5] - чело [6] (опущение актанта в семантической функции 'пациентив').

Многочисленными являются случаи опущения исходных сирконстант и наречий-сирконстант при глагольных предикатах действия: the crowd was famish'd by degrees [5] - всех голод выкосил [6] (сирконстанта образа действия); the moon, their mistress, had expir'd before [5] померкла их владычица луна [6] (наречие-сирконстанта времени); then again with curses cast them down upon the dust [5] - с проклятьями в пыли они катались [6] (наречие-сирконстанта времени - 2 единицы).

Случаи опущения частиц-предикатов являются единичными: even dogs assail'd their masters [5] - псы хозяев грызли [6], (усилительная частица).

Таким образом, применение методики семантикоструктурного анализа переводческих преобразований позволяет проникнуть в саму суть трансформационных операций, осуществлённых переводчиком. На основе количественной и качественной характеристики переводческих преобразований становится возможным выявление доминантных языковых черт в структуре языковой личности конкретного переводчика.

\section{ЛИТЕРАТУРА}

1. Караулов Ю.Н. Русский язык и языковая личность. М.: ЛКИ, 2010. 264 с.

2. Сухих С.А. Прагмалингвистическое измерение коммуникативного процесса. Дисс. ... доктора филол. наук. Краснодар, 1998. 257 с.

3. Богданов В.В. Семантико-синтаксическая организация предложения. Л.: Изд-во Лру, 1976. 204 с.

4. Васильев Л.Г. Падежные грамматики в американском языкознании. Семантико-функциональная грамматика в лингвистике и лингводидактике: Мат-лы Всероссийской научно-методич. конференции. 21-22 октября 2016 г. / Воронеж: Воронежский гос. ун-т, 2016. С. 48-56.

5. Poetry foundation. Poems and poets. 'Darkness' by Lord Byron. URL: https://www.poetryfoundation.org/poems, свободный доступ. Проверено 19.12 .2021 г.

6. Байрон Дж.Г. Паломничество Чайльд-Гарольда. Пермь: Пермское Книжное Издательство, 1988. С. 376-378.

(c) Павленко Александр Игоревич (pavlenko199507@mail.ru). 